Int. J. Electrochem. Sci., 13 (2018) 9964 - 9980

\title{
Synthesis and Characterization of Four Random copolymers Containing Fluorene as Electron Donors and Benzotriazole, Benzothiadiazole, Pyrido[3,4-b]pyrazine as Electron Acceptors
}

\author{
Shuang Chen ${ }^{1,2}$, Lingqian Kong ${ }^{3}$, Chaolei Ban ${ }^{4}$, Jinsheng Zhao ${ }^{2, *}$, Hongmei Du ${ }^{2, *}$ \\ ${ }^{1}$ College of Chemical Engineering, China University of Petroleum (East China), QingDao, 266580, P. \\ R. China. \\ ${ }^{2}$ Shandong Key Laboratory of Chemical Energy Storage and Novel Cell Technology, Liaocheng \\ University, Liaocheng, 252059, P. R. China. \\ ${ }^{3}$ Dongchang College of Liaocheng University, Liaocheng 252000, P.R. China \\ ${ }^{4}$ School of Meterials Science and Technology, Liaocheng University, Liaocheng, 252059, 252059. \\ P.R. China. \\ *E-mail: j.s.zhao@163.com, duhongmei@1cu.edu.cn
}

doi: $10.20964 / 2018.10 .16$

Received: 5 June 2018 / Accepted: 17 July 2018 / Published: 1 September 2018

Four copolymers, poly(fluorene-pyrido[3,4-b]pyrazine) (PFPP), poly(benzotriazole-fluorenepyrido[3,4-b]pyrazine) (PBTFPP), poly(benzotriazole-fluorene-benzothiadiazole) (PBTFBD), poly(benzothiadiazole-fluorene-benzothiadiazole) (PBDFBD)were synthesized successfully. Afterwards, a series of characterization, including cyclic voltammetry (CV), spectroelectrochemistry, kinetics, colorimetry and thermal gravimetric analysis were carried out to fully investigate the properties of the copolymers we got. Their band gaps are $1.87 \mathrm{eV}, 1.91 \mathrm{eV}, 1.97 \mathrm{eV}$ and $1.98 \mathrm{eV}$, respectively. From neutral state to oxidized state, PFPP changes from thistle to transparent gray, PBTFPP changes from tan to transparent gray, PBTFBD changes from sienna to lightslategray, and PBDFBD changes from rosybrown to lightgrey. The coloration efficiencies are $269.91 \mathrm{~cm}^{2} \cdot \mathrm{C}^{-1}$ for PFPP, $177.45 \mathrm{~cm}^{2} \cdot \mathrm{C}^{-1}$ forPBTFPP, $241.92 \mathrm{~cm}^{2} \cdot \mathrm{C}^{-1}$ for PBTFBD, and $174.67 \mathrm{~cm}^{2} \cdot \mathrm{C}^{-1}$ for PBDFBD in near infrared region. Except for PFPP, all the other three copolymers are stable and could be good candidates in electrochromic application.

Keywords: fluorene; pyrido[3,4-b]pyrazine; benzotriazole; benzothiadiazole; conducting polymers.

\section{FULL TEXT}

(C) 2018 The Authors. Published by ESG (www.electrochemsci.org). This article is an open access article distributed under the terms and conditions of the Creative Commons Attribution license (http://creativecommons.org/licenses/by/4.0/). 